\title{
Risk of connective tissue disease and related disorders among women with breast implants: a nation-wide retrospective cohort study in Sweden
}

Olof Nyrén, Li Yin, Staffan Josefsson, Joseph K McLaughlin, William J Blot, Martin Engqvist, Lars Hakelius, John D Boice Jr, Hans-Olov Adami

\begin{abstract}
Objective: To examine the relation between connective tissue disease and related conditions and breast implants.

Design: Retrospective cohort study of all women in the Swedish national inpatient registry who underwent breast augmentation surgery with artificial implants during 1964-93, compared with women who underwent breast reduction surgery during the same period.

Setting: Sweden.

Subjects: 7442 women with implants for cosmetic reasons or for reconstruction after breast cancer surgery and 3353 women with breast reduction surgery.

Main outcome measures: Subsequent hospitalisation for definite connective tissue diseases (rheumatoid arthritis, systemic lupus erythematosus, systemic sclerosis, dermatomyositis, and Sjögren's syndrome) or related disorders.

Results: 29 women with implants were hospitalised for definite connective tissue disease compared with 25.5 expected based on general population rates (standardised hospitalisation ratio 1.1 (95\% confidence interval 0.8 to 1.6)). There were no diagnoses of systemic sclerosis, and no significant excess in risk for polymyalgia rheumatica, fibromyalgia, and several related disorders. Among women who underwent breast reduction surgery, 14 were hospitalised for definite connective tissue disease compared with 10.5 expected (standardised hospitalisation ratio 1.3 (0.7 to 2.2$)$ ). Compared with the breast reduction group, women with breast implants showed a slight reduction for all definite connective tissue disease (relative risk 0.8 (95\% confidence interval 0.5 to 1.4 )).

Conclusions: This large nationwide cohort study shows no evidence of association between breast implants and connective tissue disease.
\end{abstract}

\section{Introduction}

Soon after the introduction of breast augmentation prostheses with silicone gel or saline contained in a silicone envelope ${ }^{1}$ anecdotal reports appeared in the literature suggesting an association between these implants and immunological disorders. Most cases were characterised by a poorly defined syndrome,

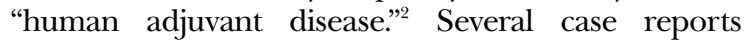
claimed an association with specific connective tissue diseases, notably systemic sclerosis. ${ }^{3}$ Some investigators suggested the possibility of an association with a yet undefined form of connective tissue disease. ${ }^{45}$

In contrast to these case reports, most epidemiological studies have been unable to confirm an excess risk. ${ }^{6-11}$ Only one study reported a small but significant excess of self reported connective tissue disease. ${ }^{12}$ These epidemiological studies, however, have generally had limited statistical power to detect modest increases in risk of any specific connective tissue disease, although meta-analyses have also failed to demonstrate any excess risk. ${ }^{6-8}$

While the number of published epidemiological studies has grown rapidly, data from large cohort studies are scarce; moreover, most studies have been conducted in North America, where extensive publicity and litigations may pose threats to both internal and external validity. Therefore, our aim was to test the hypothesis that breast implants are a risk factor for connective tissue diseases in a large, population based, prospective study in Sweden, where little publicity has occurred.

\section{Methods}

The study was approved by the Ethics Committee of Faculty of Medicine, Uppsala University, and by the Swedish Data Inspection Board.

\section{Registries}

The Swedish inpatient register, established in 1964 and with complete national coverage from 1987 onwards, stores data on individual hospital discharges. ${ }^{13}{ }^{14}$ Each record corresponds to one hospital admission and contains, in addition to the patient's national registration number (a unique identifier assigned to all Swedish residents), the dates of admission and discharge, and discharge diagnoses coded according to ICD-8 through 1986 and ICD-9 thereafter (international classification of diseases, eighth and ninth
See editorial by

Cooper and Dennison and $p 477$

Department of Medical

Epidemiology,

Karolinska Institute, PO Box 281, S-171

77 Stockholm, Sweden

Olof Nyrén, associate professor Li Yin, statistician Staffan Josefsson, programmer

International Epidemiology Institute, Rockville, Maryland, USA Joseph K

McLaughlin, senior scientist William J Blot, senior scientist John D Boice Jr, senior scientist

National Board of Health and Welfare, Stockholm, Sweden Martin Engqvist, register coordinator

Department of Plastic and Hand Surgery, University Hospital, Uppsala, Sweden

Lars Hakelius, professor

Department of Epidemiology, Harvard School of Public Health, Boston,

Massachusetts, USA Hans-Olov Adami, adjunct professor

Correspondence to: Dr Nyrén Olof.Nyrén@ mep.ki.se

BMJ 1998;316:417-22 
revisions respectively). Further, each record lists up to 10 surgical codes.

\section{Breast implant cohort}

We identified all records in the inpatient register between 1965 and 1993 that contained a surgical code for breast augmentation with foreign material (procedure codes 3853-3855). We then identified the first hospitalisation for such a breast implant procedure and each associated national registration number $(\mathrm{n}=7632)$. Cross linkage within the inpatient register selected all hospitalisations, both before and after implant surgery, for each of these national registration numbers. We linked the resulting file to the register of the total population, the migration register, and the death register.

National registration numbers that could not be found in any of these three registers $(n=93,1 \%)$ were deemed to represent records with a miscoded identifier and were deleted. We also excluded 29 records with date of death or of emigration before date of admittance, no operation confirmed, or inconsistent gender code; 25 patients with a definite connective tissue disease (see list in table 1) diagnosed before or within one month of the first hospital admission for breast augmentation; 42 patients who entered the study less than 30 days before the end of follow up (31 December 1993); and 1 patient who emigrated between the operation and the start of follow up.

After these exclusions, 7442 women who had received breast implants remained and formed the study cohort $(97 \%$ of the original national registration numbers). We divided this cohort into a subcohort with breast reconstruction after breast cancer surgery (procedure codes 3854-55, or 3853-55 with a previous or concurrent diagnosis of breast cancer ascertained through record linkage with the national cancer register 1958-92; $\mathrm{n}=3942$ ) and a subcohort with breast implants for other reasons, mainly cosmetic (procedure code 3853 , excluding those with a previous diagnosis of breast cancer; $n=3500$ ).

We reviewed the medical records of 2500 of these patients, who constituted a random sample of the subjects who were also enrolled in a separate ongoing interview study. The types of breast implant used in these patients were filled with silicone gel $(56 \%)$, filled with saline $(24 \%)$, double lumen $(12 \%)$, or unknown (7\%). Less than $0.1 \%$ of the implants were coated with polyurethane.

\section{Breast reduction cohort}

We identified 35192 unique national registration numbers recorded in the inpatient register in association with breast reduction surgery (procedure codes 3850-3851) between 1965 and 1993. We excluded 597 records with invalid national registration numbers; 67 national registration numbers with date of death or emigration before the date of hospital admittance, or inconsistent gender codes; 461 patients who underwent operations at hospitals where no breast implant surgery was done; 198 patients with prevalent connective tissue disease; 7 patients who died or emigrated between the date of operation and start of follow up; and 194 patients who entered the study less than 30 days before the end of follow up. This left 33668 women.
From this group we randomly selected one women as a control for each of the women with cosmetic breast implants: these women were matched for hospital, age (within the same 5 year group), and calendar year (within 2 years) at operation. For 147 patients with cosmetic implants, there were no eligible control patients, so the total number of patients with breast reduction in the comparison cohort was 3353 .

\section{Follow up}

Follow up began on 1 January 1972 or, if the first breast implant or breast reduction operation occurred in 1972 or later, one month after the date of discharge. Censoring occurred at date of emigration, death, or end of follow up (31 December 1993), whichever occurred first. In five counties-representing about 960000 inhabitants-the inpatient register lacked national registration numbers during one or two years (1984-6). Women living in these counties were censored during these years because they could not be followed up but were re-entered thereafter. In the analysis of total risk of definite connective tissue disease, a woman was censored after the first occurrence of any of these diseases. Since a woman could have more than one connective tissue disease, the sum of occurrences across the individual specified diseases could be greater than that for all connective tissue diseases.

We identified all hospitalisations of subjects for connective tissue disease- both definite connective tissue disease and related conditions (see table 1) occurring after their entry into the study.

\section{Statistical analyses}

Comparison of observed and expected numbers of cases We compared the observed numbers of hospitalisations for connective tissue disease and related conditions with the expected numbers of these events. To calculate the expected values, we counted the national rates of first hospitalisations by age (in 5 year groups), sex, and calendar year, firstly for each of the single specified diagnoses and then for all the definite connective tissue diseases (see table 1) combined, and then multiplied the observed number of person years by these national rates. We used the standardised hospitalisation ratio (the ratio of observed to expected numbers of first hospitalisations) as a measure of relative risk and calculated 95\% confidence intervals by assuming that the number of observed events followed a Poisson distribution. ${ }^{15}$

In individual counties we often observed peaks in age specific number of hospitalisations for connective tissue disease during the first years after inpatient registration started. This was most probably because we were unable to distinguish between incident and prevalent cases (it was not possible to know if a patient had been hospitalised before the inpatient registration started). We therefore excluded the first two years of inpatient registration in each county and thereafter counted only those hospitalised patients who had no connective tissue disease recorded during the excluded years. In addition, we used a start date of 1972 since by then the hospitalisation rates for connective tissue diseases had become stable. 
Table 1 Connective tissue diseases and related conditions of interest in study of Swedish women who had undergone breast augmentation or breast reduction

\begin{tabular}{|c|c|c|}
\hline \multirow[b]{2}{*}{ Diagnosis } & \multicolumn{2}{|c|}{ ICD codes } \\
\hline & ICD-8 & ICD-9 \\
\hline \multicolumn{3}{|l|}{ Definite connective tissue } \\
\hline Sjögren's syndrome & 734,90 & $710 \mathrm{C}$ \\
\hline Systemic lupus erythematosus & 734,10 & $710 \mathrm{~A}$ \\
\hline Systemic sclerosis (scleroderma) & $\begin{array}{l}734,00 \\
734,01 \\
734,09\end{array}$ & $710 \mathrm{~B}$ \\
\hline Dermatomyositis & 716,00 & $710 \mathrm{D}$ \\
\hline Rheumatoid arthritis & $\begin{array}{l}712,00 \\
712,10 \\
712,20 \\
712,38 \\
712,39\end{array}$ & $\begin{array}{l}714 A \\
714 B \\
714 C \\
714 D \\
719 D \\
\end{array}$ \\
\hline \multicolumn{3}{|l|}{ Related diseases under study } \\
\hline Polymyalgia rheumatica & 446,38 & 725 \\
\hline Polymyositis & 716,10 & $710 \mathrm{E}$ \\
\hline Other specified connective tissue disease & 734,98 & $710 W$ \\
\hline $\begin{array}{l}\text { Connective tissue disease or collagenosis } \\
\text { without further specification }\end{array}$ & $\begin{array}{l}734,91 \\
734,99\end{array}$ & $710 \mathrm{X}$ \\
\hline Temporal arteritis & 446,30 & $446 \mathrm{~F}$ \\
\hline Hashimoto's thyreoiditis & 245,03 & $245 \mathrm{C}$ \\
\hline Ankylosing spondylitis & 712,40 & $720 \mathrm{~A}$ \\
\hline Psoriatic arthritis & 696,00 & $\begin{array}{l}713 D^{*} \\
696 A^{*}\end{array}$ \\
\hline Myasthenia gravis & 733,00 & $358 \mathrm{~A}$ \\
\hline Sarcoidosis & 135 & 135 \\
\hline Amyloidosis & 276,99 & $277 \mathrm{D}$ \\
\hline Wegener's granulomatosis & 446,20 & $446 \mathrm{E}$ \\
\hline $\begin{array}{l}\text { Fibrositis (rheumatic) or other forms of rheumatism } \\
\text { (referred to as fibromyalgia) }\end{array}$ & $\begin{array}{l}712,50 \\
717,98 \\
718,99\end{array}$ & $729 \mathrm{~A}$ \\
\hline Discoid lupus & 695,40 & $695 \mathrm{E}$ \\
\hline Limited scleroderma & 701,00 & $701 \mathrm{~A}$ \\
\hline
\end{tabular}

${ }^{*}$ Both codes required for diagnosis.

\section{Direct comparison of observed numbers of cases}

We made direct comparisons between the patients who had had breast implants and those who had undergone breast reduction, using rate ratios as the measure of relative risk. In these analyses we corrected or excluded all erroneous and pre-existing (prevalent) diagnoses in both cohorts (see below). Using multiplicative multivariate models based on Poisson distribution, ${ }^{16}$ we adjusted for age (in five age groups $<25$ years, $25-34,35-44,45-54, \geqslant 55$ years) and, when necessary, follow up time. We also considered adjustments for year of operation, geographical region, and hospital type (local, county, or regional referral hospital), but none of these variables was significantly associated with the risk of developing any of the studied diseases (data not shown).

\section{Validation}

To evaluate possible misclassification of connective tissue diseases and related diseases in the study cohorts, we reviewed the case records for each recorded admission for every disease under consideration. We also scrutinised the medical records for the breast operations to ensure that the diseases of interest did not start before the surgery.

We found that 14 of the patients with breast implants and six of those with breast reduction did not have the disease that was recorded in the inpatient register. In some cases the true diagnosis was another connective tissue disease, but in others it was a totally unrelated condition. Among the cases with more than one connective tissue disease, all but two had ultimately been classified as having only one of the diseases. In two cases (both with diagnoses of systemic lupus erythematosus and Sjögren's syndrome), the correct diagnosis remained unclear. For 18 of the patients with breast implants and three of those with breast reduction, the recorded diseases were found to be already present at the time of the breast operation, contrary to the information in the inpatient register. The two patients with both systemic lupus erythematosus and Sjögren's syndrome belonged to this category.

We did not review the records for the entire population of the inpatient register used to calculate expected numbers of hospitalisations, so that any cases of misclassified or pre-existing disease were not corrected or excluded from the calculations of standardised hospitalisation ratios. However, in our direct comparison between the patients who had had breast implants and those who had undergone breast reduction we corrected or excluded misclassified or pre-existing diseases similarly in both cohorts.

\section{Results}

Table 2 shows the background characteristics of the subjects. Those in the breast implant cohort were followed for an average of 8 years, corresponding to 59592 person years at risk. The women with breast reduction were followed an average of 9.9 years, thus accumulating 33288 person years.

\section{Comparison of observed and expected numbers of cases}

Definite connective tissue diseases

Table 3 compares the observed and expected numbers of cases of the definite connective tissue diseases listed in table 1. According to the inpatient register, 29 patients with breast implants developed one or more of the diseases compared with 25.5 expected cases

Table 2 Background characteristics of women identified as having breast augmentation with implants or breast reduction in the Swedish inpatient discharge register during 1964-93 (values are numbers of subjects unless stated otherwise)

\begin{tabular}{|c|c|c|c|c|}
\hline & \multicolumn{3}{|c|}{ Breast implants } & \multirow[b]{2}{*}{$\begin{array}{l}\text { Breast reduction } \\
\quad(\mathrm{n}=3353)\end{array}$} \\
\hline & $\begin{array}{c}\text { For cosmetic } \\
\text { reasons } \\
(\mathrm{n}=3500)\end{array}$ & $\begin{array}{l}\text { For breast } \\
\text { reconstruction* } \\
(n=3942)\end{array}$ & $\begin{array}{c}\text { All } \\
(n=7442)\end{array}$ & \\
\hline Mean follow up (years) & 10.3 & 6.0 & 8.0 & 9.9 \\
\hline Person years & 35877 & 23715 & 59592 & 33288 \\
\hline \multicolumn{5}{|l|}{ Age at entryt: } \\
\hline$<25$ years & 782 & 22 & 804 & 774 \\
\hline 25-34 years & 1642 & 215 & 1857 & 1521 \\
\hline $35-44$ years & 797 & 1127 & 1924 & 774 \\
\hline $45-54$ years & 233 & 1623 & 1856 & 199 \\
\hline$\geqslant 55$ years & 46 & 955 & 1001 & 85 \\
\hline \multicolumn{5}{|l|}{ Year of entryt: } \\
\hline$\leqslant 1976$ & 742 & 28 & 779 & 645 \\
\hline $1977-81$ & 631 & 415 & 1043 & 590 \\
\hline $1982-86$ & 880 & 1106 & 1479 & 838 \\
\hline $1987-93$ & 1247 & 2393 & 3629 & 1280 \\
\hline
\end{tabular}

${ }^{\star}$ After treatment for breast cancer.

†Entry (start of follow up) is defined by date at first breast implant or breast reduction surgery noted in the register. 
Table 3 Observed numbers of Swedish women with breast implants or breast reduction who developed definite connective tissue disease, and comparison of observed and expected numbers by standardised hospitalisation ratios

\begin{tabular}{|c|c|c|c|c|c|c|c|c|}
\hline \multirow[b]{3}{*}{$\begin{array}{l}\text { Category of definite } \\
\text { connective tissue disease }\end{array}$} & \multicolumn{6}{|c|}{ Breast implant } & & \\
\hline & \multicolumn{2}{|c|}{ Cosmetic } & \multicolumn{2}{|c|}{ Reconstruction } & \multicolumn{2}{|r|}{ All } & \multicolumn{2}{|c|}{ Breast reduction } \\
\hline & $\begin{array}{l}\text { No of } \\
\text { cases* }\end{array}$ & SHR $(95 \% \mathrm{CI})$ & $\begin{array}{l}\text { No of } \\
\text { cases }^{*}\end{array}$ & SHR (95\% CI) & $\begin{array}{l}\text { No of } \\
\text { cases* }\end{array}$ & SHR $(95 \% \mathrm{Cl})$ & $\begin{array}{l}\text { No of } \\
\text { cases }^{*}\end{array}$ & SHR (95\% CI) \\
\hline All & $18(6,0)$ & 1.6 (0.95 to 2.5$)$ & $11(6,2)$ & $0.8(0.4$ to 1.4$)$ & $29(12,2)$ & $1.1(0.8$ to 1.6$)$ & $14(3,1)$ & 1.3 (0.7 to 2.2$)$ \\
\hline Rheumatoid arthritis & $11(4,0)$ & $1.3(0.7$ to 2.4$)$ & $8(4,1)$ & $0.7(0.3$ to 1.4$)$ & $19(8,1)$ & $1.0(0.6$ to 1.5$)$ & $10(3,2)$ & $1.3(0.6$ to 2.4$)$ \\
\hline $\begin{array}{l}\text { Systemic lupus } \\
\text { erythematosus }\end{array}$ & $5(2,0)$ & $2.3(0.7$ to 5.3$)$ & $2(1,1)$ & $1.2(0.1$ to 4.2$)$ & $7(3,1)$ & 1.8 (0.7 to 3.7$)$ & $3(0,0)$ & $1.5(0.3$ to 4.3$)$ \\
\hline Scleroderma & 0 & $0 \quad(0$ to 4.6$)$ & $1(1,0)$ & $1.6(0.0$ to 9.0$)$ & $1(1,0)$ & $0.8(0.0$ to 4.4$)$ & $3(0,0)$ & $5.0(1.0$ to 14.7$)$ \\
\hline Sjögren's syndrome & $3(2,0)$ & 5.0 (1.0 to 14.5$)$ & 0 & $0 \quad(0$ to 2.9$)$ & $3(2,0)$ & $1.8(0.4$ to 5.4$)$ & 0 & (0 to 5.3) \\
\hline Dermatomyositis & $1(0,0)$ & $7.3(0.2$ to 40.5$)$ & 0 & $0 \quad$ (0 to 19.5) & $1(0,0)$ & $3.4(0.1$ to 19.1$)$ & 0 & (0 to 23.5) \\
\hline
\end{tabular}

SHR=standardised hospitalisation ratio.

*Values are No of cases according to inpatient register (No of cases already prevalent at time of surgery, No of cases misclassified according to medical record review).

(standardised hospitalisation ratio 1.1 (95\% confidence interval 0.8 to 1.6$)$ ). There was no significant excess risk for systemic lupus erythematosus or Sjögren's syndrome: in most of the cases of both diagnoses, the disease either already existed at the time of the breast augmentation or was misclassified. An excess of dermatomyositis was based on only one case. A single case of scleroderma corresponded to the expected number, but our review of the medical record revealed that the disease was already present before the operation.

In the cohort of women with breast reduction surgery there were 14 cases of definite connective tissue disease recorded in the inpatient register compared with 10.5 expected cases (standardised hospitalisation ratio 1.3 (0.7 to 2.2$)$ ). We noted a marginally significant excess risk for scleroderma in these women (3

Table 4 Observed numbers of Swedish women with breast implants or breast reduction who developed non-definite connective tissue disease, and comparison of observed and expected numbers by standardised hospitalisation ratios

\begin{tabular}{|c|c|c|c|c|}
\hline \multirow[b]{2}{*}{ Disease category } & \multicolumn{2}{|c|}{ Breast implant } & \multicolumn{2}{|c|}{ Breast reduction } \\
\hline & $\begin{array}{l}\text { No of } \\
\text { cases* }^{*}\end{array}$ & SHR $(95 \%$ Cl) & $\begin{array}{l}\text { No of } \\
\text { cases* }^{*}\end{array}$ & SHR $(95 \% \mathrm{Cl})$ \\
\hline Polymyositis & $1(0,1)$ & $1.7(0.0$ to 9.4$)$ & 0 & $0 \quad(0$ to 12.7$)$ \\
\hline Polymyalgia rheumatica & $6(0,1)$ & $1.4(0.5$ to 3.1$)$ & $1(0,1)$ & $1.0(0.0$ to 5.6$)$ \\
\hline Polyarteritis nodosa & $1(0,1)$ & $3.1(0.1$ to 17.3$)$ & 0 & $0 \quad$ (0 to 22.9) \\
\hline Temporal arteritis & $1(0,0)$ & $0.6(0.0$ to 3.4$)$ & 0 & $0 \quad(0$ to 8.0$)$ \\
\hline Other specified connective tissue disease & $2(0,2)$ & $1.4(0.2$ to 5.2$)$ & $1(0,1)$ & $1.2(0.0$ to 6.9$)$ \\
\hline $\begin{array}{l}\text { Connective tissue disease or collagenosis } \\
\text { without further specification }\end{array}$ & $5(1,1)$ & $1.4(0.5$ to 3.2$)$ & 0 & $0 \quad$ (0 to 2.0) \\
\hline Sarcoidosis & $2(0,0)$ & $0.6(0.1$ to 2.1$)$ & $2(0,0)$ & $1.2(0.1$ to 4.2$)$ \\
\hline Localised lupus & $1(0,0)$ & $2.0(0.1$ to 11.4$)$ & $1(0,1)$ & $3.8(0.1$ to 21.3$)$ \\
\hline Ankylosing spondylitis & $3(2,1)$ & $1.4(0.3$ to 4.2$)$ & 0 & $0 \quad(0$ to 2.5$)$ \\
\hline Fibromyalgia & $14(1,5)$ & $1.6(0.9$ to 2.7$)$ & $5(0,1)$ & $1.3(0.4$ to 3.0$)$ \\
\hline Psoriatic arthritis & 0 & $0 \quad(0$ to 3.2$)$ & $2(0,0)$ & $4.3(0.5$ to 15.4$)$ \\
\hline
\end{tabular}

SHR=standardised hospitalisation ratio.

*Values are No of cases according to inpatient register (No of cases already prevalent at time of surgery, No of cases misclassified according to medical record review)

Table 5 Relative risks of definite connective tissue diseases and fibromyalgia among 7442 women with breast implants compared with 3353 women with breast reduction

\begin{tabular}{lccc} 
& \multicolumn{2}{c}{ Observed No of cases } & \\
\cline { 2 - 3 } Disease category & $\begin{array}{c}\text { Breast } \\
\text { implant }\end{array}$ & $\begin{array}{c}\text { Breast } \\
\text { reduction }\end{array}$ & Relative risk (95\% Cl)* \\
\hline All definite connective tissue diseases & 16 & 11 & $0.8(0.5$ to 1.4$)$ \\
\hline Rheumatoid arthritis & 11 & 5 & $1.3(0.7$ to 2.5$)$ \\
\hline Systemic lupus erythematosus & 3 & 3 & $0.7(0.3$ to 1.6$)$ \\
\hline Fibromyalgia & 9 & 5 & $1.0(0.3$ to 3.0$)$ \\
\hline
\end{tabular}

*Adjusted for age and, when appropriate, length of follow up. observed cases, standardised hospitalisation ratio 5.0 (1.04 to 14.7)).

\section{Non-definite connective tissue diseases}

We observed no remarkable findings with regard to the other diseases under study, and table 4 shows results only for those diseases that occurred during follow up.

Among the women with breast implants there were no cases of Hashimoto's thyroiditis, myasthenia gravis, Wegener's granulomatosis, psoriatic arthritis, amyloidosis, or limited scleroderma. The few cases of polyarteritis nodosa and ankylosing spondylitis found were either prevalent at the time of breast augmentation or were misclassified. Six cases of polymyalgia were recorded, but the standardised hospitalisation ratio of 1.4 was non-significant. Excesses for polymyositis and polyarteritis nodosa were each based on no more than one observed case, and neither diagnosis was correct. Five patients had a diagnosis of connective tissue disease that could not be classified as clearly belonging to any of the existing categories (standardised hospitalisation ratio 1.4 (0.5 to 3.2$)$ ), but in one case the diagnosis was clearly inappropriate and in another the symptoms were present at time of the operation. The excess for fibromyalgia (standardised hospitalisation ratio 1.6 (0.9 to 2.7)) was based on 14 cases, of which six were found to be due to disease existing before the operation or misclassification.

In the cohort of patients with breast reduction the excess for fibromyalgia (standardised hospitalisation ratio 1.3 (0.4 to 3.0)) was based on five cases, one of which was misclassified. A non-significant excess risk for psoriatic arthritis (standardised hospitalisation ratio 4.3 (0.5 to 15.4)) was based on only two observed cases.

For the disease categories with the largest number of cases, we were able to perform stratified analyses by the interval between the operation and hospitalisation for the disease. We found no clear indications of non-uniform risk with length of follow up among the women with breast implants (data not shown). Similarly, stratification by age at operation (below median age $v$ above median age) and calendar year of operation (before median year $v$ after median year) did not reveal any important differences (data not shown).

\section{Direct comparison of observed numbers of cases}

Direct comparisons between the patients who had had breast implants and those who had undergone breast reduction enabled us to correct for cases of 
pre-existing or misclassified disease (since the corrections were done in both groups of women). Table 5 shows the relative risks, adjusted for age and, when appropriate, follow up time, for the largest disease categories. The relative risk of any definite connective tissue disease in the cohort with breast implants was 0.8 . There was a non-significant 30\% excess risk for rheumatoid arthritis, but a similar deficit for systemic lupus erythematosus. The estimated risk for fibromyalgia was identical in the two cohorts.

\section{Discussion}

This large, nationwide study supports the overall conclusion from formal epidemiological studies that breast implants are not associated with a meaningful excess risk of connective tissue diseases. ${ }^{6-11}$ Moreover, the study provides results from a population outside North America, where most studies have been performed, adding further consistency to the findings. ${ }^{17}$ In our study the standardised hospitalisation ratio for definite connective tissue disease was 1.1 (upper 95\% confidence limit 1.6). A direct comparison between the women with breast implants and those with breast reduction also revealed no increased risk of definite connective tissue disease in the former cohort (relative risk 0.8 (95\% confidence interval 0.5 to 1.4$)$ ).

The strengths of our study include the cohort design, the relatively large study size, the population based approach, the use of doctors' notations rather than self reporting for information on exposure and outcome, and the virtually complete follow up. Moreover, the media coverage of the alleged adverse effects of silicone implants has been limited in Sweden, thus lessening the risk of bias in ascertainment and reporting. However, notwithstanding the fact that our exposed cohort was close to seven times as large as that reported by Sánchez-Guerrero et al, ${ }^{9}$ we had a limited ability to detect a modest increase in the risk of rare diseases such as scleroderma, the disease most often implicated in the literature. But recent large casecontrol studies of scleroderma have found no increase in risk, ${ }^{10}$ further indicating that the risk of this disease among women with implants is of little or no concern.

\section{Limitations of study}

An important caveat is that our study end point was restricted to care in hospital for the diseases under study. Thus, women with connective tissue disease who were managed only as outpatients could not be identified. Nor were we able to identify women with connective tissue disease who did not seek medical advice or who were incorrectly given a diagnosis not among the ones that we searched for. Hospitalised cases are likely to represent the most serious examples of the disease. However, an advantage of counting only hospitalised patients, who are likely to become more thoroughly investigated, is a higher specificity of the diagnosis compared with self reported connective tissue disease or disease diagnosed in an ambulatory care setting. Moreover, because women with a breast implant are already under medical surveillance, they may be more rather than less likely to have a connective tissue disease diagnosed, which would bias risk estimates upwards. ${ }^{18}$

Our detailed review of medical records showed that several of the diagnoses recorded in the inpatient reg-
- Anecdotal reports have suggested that silicone breast implants may cause immunological disorders

- In a nationwide study of over 7000 Swedish women with breast implants and a control group of over 3000 women who had undergone breast reduction surgery, we found no excess risk for connective tissue disease

- Of the women with implants, 29 were hospitalised for connective tissue disease compared with the 25.5 expected from national hospital discharge rates, while, of those who underwent breast reduction, 14 were hospitalised compared with the 10.5 expected

- Direct comparison of the two groups of women showed that those with implants had a slightly lower risk of connective tissue disease

- There is little likelihood of an association between breast implants and connective tissue disease

ister were incorrect. Some diagnoses were given at departments where a patient was hospitalised for nonrheumatological reasons and the patient's own reports about previous diagnoses were accepted uncritically. The presence of incorrect diagnoses affected not only the women with breast implants and breast reduction but also the national rates. The nature of such misclassification of outcome is not known, but it seems likely to be non-differential so that its effect on the standardised hospitalisation ratios should be small. ${ }^{19}$ Indeed, our direct comparison between the women with breast implants and those with breast reduction, when we made diagnostic corrections with equal completeness in both groups, also showed no association between connective tissue diseases and breast implants.

\section{Conclusions}

This nationwide study revealed no excess of connective tissue disease among over 7000 Swedish women with breast implants followed for an average of eight years. The consistent absence of excess risks compared with two different comparison populations reinforces the credibility of the findings. Thus, our data add to the emerging consensus that there is no important association between breast implants and connective tissue disease.

Contributors: ON, the principal investigator and guarantor of the paper, initiated the research, discussed the core ideas, designed the protocol, coordinated record linkages and abstraction field work, outlined and coordinated analyses, and wrote most of the paper. LY performed most of the programming and practical analysis, discussed core ideas, participated in the field work, and edited the paper. SJ had main responsibility for programming; discussed core ideas; and participated in initiation of the research, data collection, field work, analyses, and editing of the paper. JKMcL initiated the research; discussed the core ideas; formulated the primary study hypothesis; and participated in protocol design, analysis and interpretation of data, and writing of the paper. WJB initiated the research; discussed core ideas; and participated in formulation of the primary study hypothesis, protocol design, data interpretation, and editing of the paper. ME discussed core ideas; performed the programming needed for selection of cohorts; calculated national 
incidences of connective tissue diseases; and participated in the study design, data interpretation, and editing of the paper. LH discussed core ideas and participated in initiation of the study, formulation of the primary study hypothesis, protocol design, data interpretation, and editing of the paper.JDB discussed core ideas; made suggestions about analyses; and participated in data interpretation and editing of the paper. $\mathrm{H}-\mathrm{OA}$ initiated the research and participated in the protocol design, data interpretation and writing of the paper.

Funding: This research project was funded by the International Epidemiology Institute, which in turn received funds from the Dow-Corning Corporation.

Conflict of interest: Indirect funding from Dow-Corning Corporation.

1 Cronin TD, Gerow FJ. Augmentation mammoplasty: a new "natural feel" prosthesis. In: Transactions of the third international congress of plastic surgery. Amsterdam: Excerpta Medica Foundation, 1964:41-9.

2 Miyoshi K, Miyaoka T, Kobayashi Y, Itakura T, Nishijo K, Higashibara M, et al. Hypergammaglobulinemia by prolonged adjuvanticity in man: disorders developed after augmentation mammoplasty. Jpm Med J 1964; 2122:9-14.

3 Martin L. Silicone breast implants and connective tissue diseases: an ongoing controversy.J Rheumatol 1995;22:198-200.

4 Solomon G. A clinical and laboratory profile of symptomatic women with silicone breast implants. Semin Arthritis Rheum 1994;24(suppl 1):29-37.

Bridges AJ. Silicone implant controversy continues. Lancet 1994; Bridges AJ.
344:1451-2.

Perkins LL, Clark BD, Klein PJ, Cook RR. A meta-analysis of breast implants and connective tissue diseases. Ann Plast Surg 1995;35:561-70.
7 Wong O. A critical assessment of the relationship between silicone breast implants and connective tissue diseases. Regul Toxicol Pharmacol 1996;23:74-85.

8 Hochberg MC, Perlmutter DL. The association of augmentation mammoplasty with connective tissue disease: A meta-analysis. Curr Top Microbiol Immunol 1996;210:411-7.

9 Sánchez-Guerrero J, Colditz GA, Karlson EW, Hunter DJ, Speizer FE, Liang MH. Silicone breast implants and the risk of connective-tissue diseases and symptoms. N Engl J Med 1995;332:1666-70.

10 Hochberg MC, Perlmutter DL, Medsger TA Jr, Nguyen K, Steen V, Weisman $\mathrm{MH}$, et al. Lack of association between augmentation mammoplasty and systemic sclerosis (scleroderma). Arthritis Rheum 1996;7:1125-31.

11 Burns CJ, Laing TJ, Gillespie BW, Heeringa SG, Alcser KH, Mayes MD, et al. The epidemiology of scleroderma among women: assessment of risk from exposure to silicone and silica.J Rheumatol 1996;23:1904-11.

12 Hennekens CH, Lee IM, Cook NR, Hebert PR, Karlson EW, LaMotte F, et al. Self-reported breast implants and connective-tissue diseases in female health professionals. JAMA 1996;275:616-21.

13 Patientregistret 1992/93. Stockholm: Socialstyrelsen, Epidemilogiskt Centrum, 1995. (Publication 1995-00-88.) (in Swedish)

14 Nilsson AC, Spetz C-L, Carsjö K, Nightingale R, Smedby B. Slutenvårdsregistrets tillförlitlighet. Diagnosuppgifterna är bättre än sitt rykte. Läkartidningen 1994;91:598-605. (in Swedish)

15 Bailar JC, Ederer F. Significance factors for the ratio of a Poisson variable to its expectations. Biometrics 1964;20:638-43.

16 McCullagh P, Nelder JA. Generalized linear models. London: Chapman and Hall, 1989.

17 Hill AB. The environment and disease: association or causation? Proc $R$ Soc Med 1965;58:295-300.

8 Berkson J. Limitations of the application of fourfold table analysis to hospital data. Biometrics Bull 1946;2:47-53.

19 Rothman KJ. Modern epidemiology. Boston: Little, Brown, 1986.

(Accepted 27 November 1997)

\section{Single dose vitamin A treatment in acute shigellosis in Bangladeshi children: randomised double blind controlled trial}

Shahadat Hossain, Rabi Biswas, Iqbal Kabir, Shafique Sarker, Michael Dibley, George Fuchs, Dilip Mahalanabis

Clinical Sciences

Division,

International

Centre for

Diarrhoeal Disease

Research,

Bangladesh, GPO

Box 128, Dhaka

1000, Bangladesh

Shahadat Hossain,

senior medical officer

Rabi Biswas,

research assistant

Iqbal Kabir,

scientist

Shafique Sarker,

associate scientist

George Fuchs,

director

Dilip Mahalanabis,

former director

Centre for Clinical

Epidemiology and

Biostatistics,

University of

Newcastle,

Newcastle, NSW

2300, Australia

Michael Dibley,

senior lecturer

Correspondence to:

Dr Hossain

shossain@icddrb.org

BMJ 1998;316:422-6

\section{Abstract}

Objective: To evaluate the efficacy of a single large oral dose of vitamin A in treating acute shigellosis in children in Bangladesh.

Design: Randomised double blind controlled clinical trial.

Setting: Dhaka Hospital, International Centre for

Diarrhoeal Disease Research, Bangladesh.

Subjects: 83 children aged 1-7 years with

bacteriologically proved shigellosis but no clinical signs of vitamin A deficiency; 42 were randomised to treatment with vitamin A and 41 formed a control group.

Intervention: Children were given a single oral dose of $200000 \mathrm{IU}$ of vitamin A plus 25 IU vitamin $\mathrm{E}$ or a control preparation of 25 IU vitamin $\mathrm{E}$.

Main outcome measures: Clinical cure on study day 5 and bacteriological cure.

Results: Baseline characteristics of the subjects in the two treatment groups were similar. Significantly more children in the vitamin A group than in the control group achieved clinical cure (19/42 (45\%) v 8/14 $(20 \%) ; \chi^{2}=5.14,1 \mathrm{df}, \mathrm{P}=0.02$; risk ratio $=0.68(95 \%$ confidence interval: 0.50 to 0.93$)$ ). When cure was determined bacteriologically, the groups had similar rates $\left(16 / 42(38 \%) v 16 / 41(39 \%) ; \chi^{2}=0.02,1 \mathrm{df}\right.$, $\mathrm{P}=0.89$; risk ratio $=0.98(0.70$ to 1.39$))$.
Conclusions: Vitamin A reduces the severity of acute shigellosis in children living in areas where vitamin A deficiency is a major public health problem.

\section{Introduction}

Shigellosis remains one of the most severe enteric infections affecting children in developing countries, including Bangladesh. ${ }^{12}$ It results in the frequent passage of small, bloody mucoid stools; abdominal cramps; and tenesmus caused by ulceration of the colonic epithelium. ${ }^{3-6}$ In addition to high mortality from shigellosis, the protein losing enteropathy is a serious complication that probably contributes to the malnutrition and growth stunting associated with the disease. $^{7-11}$

Reports that vitamin A supplementation reduces childhood mortality from diarrhoeal diseases and measles related diarrhoea have been published. ${ }^{12-17}$ Other studies have found reduced disease severity and lower morbidity in patients with diarrhoea treated with vitamin A. ${ }^{18-20}$ These findings are important for developing countries such as Bangladesh, where shigellosis is one of the most important contributors to childhood morbidity and mortality. Although appropriate antibiotic treatment shortens the course of shigellosis, morbidity and mortality are still high. ${ }^{21-23}$ Reports of beneficial effects of vitamin A supplementa- 